\title{
Doctor I'm desperate, my mouth is on fire! - Burning mouth syndrome, what is the role of Psychiatry?
}

Jesus, Bianca ${ }^{1}$; Correia, João Martins ${ }^{1}$; Teixeira, Ana Filipa; Gil, Tiago ${ }^{1}$; Cruz e Sousa, Diana; Ramos, Sara; Nunes, Susana Cristina ${ }^{1}$; Caetano, Ana Sofia ${ }^{1}$

1 Unidade Local de Saúde da Guarda- E.P.E., Department of Psychiatry and Mental Health, Guarda, Portugal.

\section{Introduction}

BMS is a chronic pain condition, with hot painful sensation, localized at the oral mucosa without clinically evident causes. (1-7)

The pathophysiology is poorly understood, probably a multifactorial condition, with interactions between neurophysiological and psychological factors. (1-7)

Objectives: The report of a case of burning mouth syndrome (BMS) and literature review.

\section{Materials and methods}

Review of the literature using PubMed database, over a 5-year period, and without a specific type of study. Description of a clinical case.

\section{Case report}

Identification: Woman; 68 years-old; married; retired; $4^{\text {th }}$ grade

Reason for appointment: Pain and burning in the oral mucosa and dysgeusia associated with anxiety for the past 7-years.

Chief complaint: Pain and burning sensation in the mouth and altered taste perception after a dental procedure 7 years ago.

Patient also complained about loss of pleasure in tasting food, reported feeling sad and desperate with the situation, and poor sleep quality.

\begin{tabular}{|c|c|}
\hline Psychiatric history: dysthymia & No relevant family history \\
\hline Past Medical history: dyslipidemia & No toxic habits \\
\hline $\begin{aligned} \text { Medication: } & \text { - diazepam } 5 \mathrm{mg} \\
& \text { - ginkgo biloba } 40 \mathrm{mg}\end{aligned}$ & $\begin{array}{l}\text { simvastatin } 20 \mathrm{mg} \\
\text { omeprazole } 20 \mathrm{mg}\end{array}$ \\
\hline
\end{tabular}

Mental Status Exam: Appellative attitude, depressed mood.

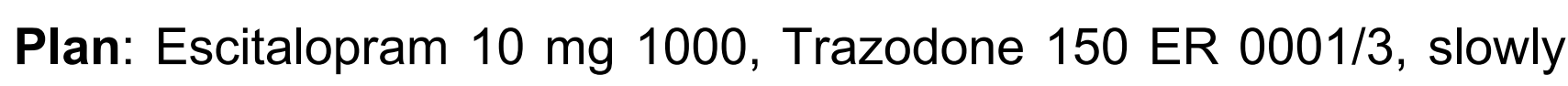
stop Diazepam $5 \mathrm{mg}$ and referral for a stomatology appointment.

2nd appointment - Patient discontinued the antidepressant after one week, as she was not feeling better and also due to side effects. It was proposed to switch to Duloxetine $60 \mathrm{mg}$ daily.

3rd appointment - The Stomatologist diagnosis was primary BMS. It was proposed Clonazepam $0.5 \mathrm{mg}$, to dissolve in the mouth (2-3 min) 2-3 times per day, not swallow, and Pregabalin $50 \mathrm{mg}$ daily. The patient stopped Clonazepam for not feeling better and stopped Duloxetine due to its' side effects. The Clonazepam $0.5 \mathrm{mg}$ prescription was changed to swallow. She refused to restart the antidepressant therapy.

Last two appointments - Patient reported a lack of symptomatic improvement, presented with depressive mood and hopelessness. She chose to keep taking Clonazepam for relaxation purposes. The importance of antidepressant treatment was reinforced. She admitted that she had stopped Duloxetine one week after start taking it as she noted no improvement. She however agreed to start Duloxetine again. In the last visit, there was a significant improvement in humor and less focus in oral complains.

\section{Results}

BMS prevalence ranges from $0.7-18 \%$, increases with age, especially among peri- and post-menopausal women. The mean age of diagnosis is 59,4 years. $(1,2)$ The classification system mostly used is by Scalla et al.: primary (essential/idiopathic) or secondary (from other clinical conditions).(1,3) The etiology of BMS remains unknow. Some authors proposed a hypothesis for a cascade of causes and mechanisms leading for primary BMS. $(1,4)$

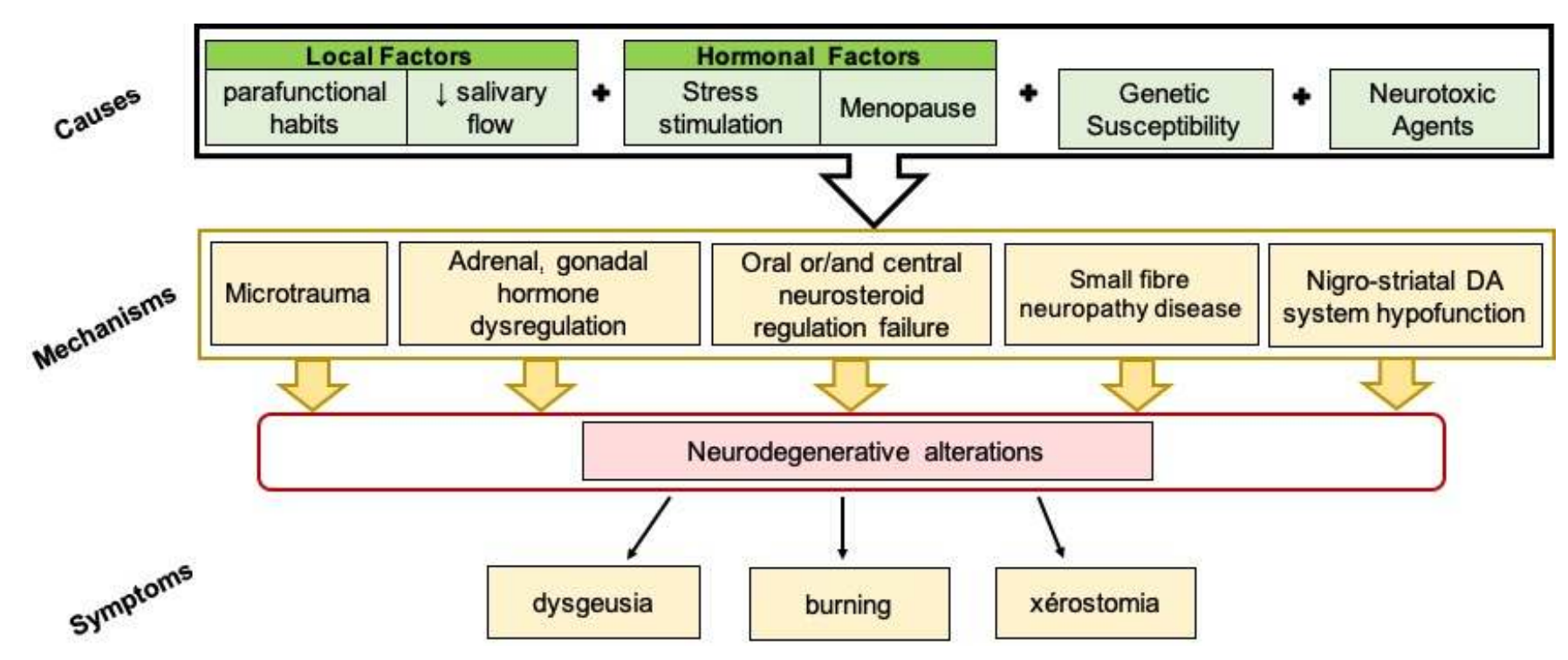

The pain is usually spontaneous, bilateral, affecting any part of the oral cavity with no associated injury or clinical manifestation. The natural history of BMS hasn't been well described.(1-3) Complete remission is rare (3\%).(4) The diagnosis is clinical and of exclusion. There is evidence of a relationship between psychological factors/psychiatric disorders and BMS but the mechanisms involved remain unclear. $(4,5)$ There is no definitive treatment however several treatment modalities, including pharmacological and non-pharmacological (eg. Psychotherapies), are available, but from a evidence-based research point of view none is entirely satisfactory. $(1-4,6,7)$

The best treatment approach for this disease is to assess the psychological and/or psychiatric characteristic of the patients and to contemplate the possible need of multidisciplinary approach. $(4,6)$

\section{Conclusions}

This case report shows the challenges in the management, diagnosis and treatment of BMS. It also demonstrates an example of high consumption of healthcare resources and a poor prognosis in terms of life's quality, while showing that the adherence to treatment relies on an effective communication with the patient as part of both as part of both the patient-doctor relationship and the therapeutic alliance.

\section{References}

1. Jääskeläinen SK, Woda A. Burning mouth syndrome. Cephalalgia. 2017;37(7):627-47.

2. Moghadam-Kia S, Fazel N. A diagnostic and therapeutic approach to primary burning mouth syndrome. Clin Dermatol. 2017;35(5):453-60.

3. Klasser GD, Grushka M, Su N. Burning Mouth Syndrome. Oral Maxillofac Surg Clin North Am. 2016;28(3):381-96.

4. Kim M, Kho H. Understanding of Burning Mouth Syndrome Based on Psychological Aspects. Chin J Dent Res. 2018;21(1):9-19.

5. Yoo HS, Jin SH, Lee YJ, Song CM, Ji YB, Tae K. The role of psychological factors in the development of burning mouth syndrome. Int J Oral Maxillofac Surg. 2018;47(3):374-8

6. de Souza IF, Mármora BC, Rados PV, Visioli F. Treatment modalities for burning mouth syndrome: a systematic review. Clin Oral Investig. 2018;

7. Liu Y, Kim Y, Yoo T, et al. Burning mouth syndrome: a systematic review of treatments. Oral Dis. 2018;24(3):325-34. 